\title{
Mathematics and outdoor photography experience - exploration of an approach to mathematical education, based on the theory of Dewey's aesthetics
}

\author{
Antje Meier ${ }^{1}$, Markku Hannula ${ }^{2}$ and Miika Toivanen ${ }^{3}$ \\ ${ }^{1}$ Volda University College, Norway \\ 2 University of Helsinki, Finland and Volda University College, Norway \\ ${ }^{3}$ University of Helsinki, Finland
}

\begin{abstract}
Based on Dewey's theory of art, aesthetics, and experiences and photographer Barnbaums' writing about expanded perception through photography, we conducted a one-day experimental mathematics education unit. Using photography in outdoor conditions had a positive impact on teacher students' perception of the use of photography for teaching mathematics. To study the changes in students' visual attention deeper, we used gaze-tracking to analyse one student's visual attention when walking outdoors after the activity. The gaze data indicated that more visual attention was given to objects he had photographed or discussed during the group activity in comparison to other objects.
\end{abstract}

Keywords: aesthetics, mathematics, photography, teacher education, visual attention

Contact: antje.meier@hivolda.no

DOI: https:// doi.org/ 10.31129/LUMAT.6.2.317

\section{Introduction}

It has been suggested (Kramer, 2013, p.11) that adventure and experimental education should be used more in mathematics teacher education, both inside and outside the classroom. Extraordinary experiences will be remembered and can give fulfilling satisfaction (Barnbaum, 2010). Dewey made a distinction between ordinary experience and an experience, which Pugh and Girod (2007, p.10) further elaborated, saying that science has the potential to enrich life through such experiences. The approach of Pugh and Girod, based on Dewey's aesthetics (Dewey, 1958), emphasises both outdoor experiences and re-seeing. For them re-seeing means looking at ordinary objects from a new perspective.

It is well known that we need to look and see in-depth when we want to take a photograph. This is the opposite to the casual everyday seeing when we “... allow visual input to slide in and out of our eyes and brain all the time" (Barnbaum, 2010, p. 58). 
What we really see depends on our background. Barnbaum stated that the more knowledge, training, and experience we have the more and deeper we will see. He used the metaphor of a detective viewing the room of a crime scene. The detective will see many more details than an ordinary person.

Visualisation, both as a process and a product, ought to become more visible in mathematics education, Arcavi claimed (2003, p. 215). He emphasises the creation, interpretation and reflection upon pictures and images.

The first author of this paper is developing a teaching unit in the spirit of designbased research (Gravemeijer, Akker, McKenny, \& Nieveen, 2006). In this unit, photography is used to develop the way students perceive mathematics in their environment. They get the task to be on thelookout for images of mathematics around them, out of school. They capture those images with their mobile phone, analyse the mathematics underlying one of them and discuss their thoughts, both in small groups and in the whole class. This paper reports an evaluation of the second iteration of this teaching unit.

Our approach is supported by an earlier study (Munakata and Vaidya, 2012), which indicates that the use of photography encourages students and increases creativity. Everyday life outdoors and science/ mathematics can be connected in a meaningful way through the experience of photography.

\section{Research questions}

To explore the effect of photography-based teaching we had the following questions:

1. How would photography-based teaching influence students' interest in and valuation of visual approaches in mathematics learning?

2. How would this influence students' perception of mathematics in everyday objects?

\section{Theory}

Our theoretical framework is mainly based on Dewey's theory of art, aesthetics and experience (Dewey, 1934; 1958). Our work is also influenced by Pugh and Girod (2007) who constructed an alternative pedagogy that emphasises transformative aesthetical experiences in everyday contexts. Moreover, the writings of photographer 
Bruce Barnbaum (2010; 2014) will add theoretical ideas about perception in photography.

In the field of education, Dewey's work is well known for learning through experiences, but Pugh and Girod (2007) argue that his concept of experiences through learning is equally important. Dewey's writings on art and aesthetics give us insight into "how learning concepts can foster enriched experience - not just in the classroom, but in everyday life" (Pugh \& Girod, 2007, p. 10).

Wong and his colleagues (Wong, Pugh, \& The Deweyan Ideas Group at Michigan State University, 2001) gave an explanation about what Dewey meant by that kind of experience. According to them, for Dewey the central goal of education is "to help students to lead lives rich in worthwhile experiences" (p. 319). Dewey makes a distinction between ordinary experience and an experience. We all have ordinary experiences all the time, but there are distractions, interruptions, we are tired or lazy and the experience ends without developing. The experience on the other hand "runs its course to fulfilment ... A piece of work is finished in a way that is satisfactory; a problem receives its solution; a game is played through .... Such an experience is a whole and carries with it its own individualizing quality and self-sufficiency. It is an experience" (Dewey, 1958, p. 35). Just such a deep satisfaction photographer Barnbaum derived from each step of his process, from discovering something worth photographing to the final print. He wrote that anything that can produce an emotionally fulfilling experience, painting, literature, music and photography, is a form of art (2013, p. 283). Dewey (1958) connected art with this kind of experience and used the term "aesthetical experience" in his writings.

Deweyan scholar Jackson (1998. p. 124) explained: "The arts, above all, teach us something about what it means to undergo an experience..." Here, art is not linked to beauty and a subjective matter of taste, but represents idealized experience. It arises when a person interacts with an object and it merges to a whole from varied parts. "Like a drama, an experience is an event that has its own completeness ..." Pugh and Girod (2007, p.11) wrote. While Dewey himself never explicitly discussed the implications of aesthetics for education, Pugh and Girod (2007) developed an educational approach, based on Dewey's thoughts. They stated that students would see the world in a new transformed way, through making their own experiences, especially in outdoor conditions. Students can get a renewed interest, excitement and clarity in mathematical concepts. The term "creative", as it is used in this paper, is 
related to this new way of seeing mathematics content. We will focus on the expansion of perception on outdoor mathematics, increasing interest, meaning and clarity in mathematical thinking.

To perceive means both to view the world with fresh eyes and to be fully alive in an experience (Wong, 2001, p. 329). Photography might be a tool to accomplish both, reseeing and to have an experience in the sense of Dewey. Deep perception, the art of re-seeing, must be taught (Barnbaum, 2010; 2014).

According to Barnbaum (2010, p. 58), the making of a photograph starts with visualisation. In depth looking and seeing, re-seeing, is the starting point of the process that leads to the product, the final print. This process can have a completeness and self-sufficiency in Dewey's sense (1934, p. 35).

“You and your eyes are not just wandering aimlessly..." Barnbaum continued. We will start to see things in areas we would have overlooked previously. We will analyse everything, learn more about our objects and provide deeper meaning to what we are seeing. "Seeing the unseen" was the leitmotif of Arcavi's writing about the role of visual representation in the learning of mathematics (Arcavi, 2003, p. 216). While visualisation for Barnbaum is the starting point of the photographer's process, Arcavi (p. 217) stated that visualisation is both the process and the product of creation, interpretation, use of and reflection upon pictures. He analysed various roles of visualisation in mathematics education with the goal of developing previously unknown ideas and advancing understanding in mathematical education. Visualisation becomes a tool for learning mathematics.

\section{$4 \quad$ Methodology}

Firstly, we will first describe the principles and design of the teaching activity in detail. In the next section we will present the survey and thirdly the gaze-tracking methodology. Finally, we reflect on the ethical issues encountered in this study.

\subsection{Particicants}

The participants in this study were fifty in-service teacher students at their first twoday meeting on a course for further education at Volda University Collage. They had varied backgrounds: some of the students were working as teachers; some had been teachers in mathematics for a long time, without enough formal education. Others 
had a teacher education, but were not practising right now. The course brings together elementary teachers (1-7 grade) and middle school teachers (5-10 grade). Both groups were roughly equal in size, 26 in 1- 7 group and 24 in the 5- 10 group.

In the elementary teacher group we chose two students to wear eye-tracking glasses (Figure 1) and microphones during three short walks outside school (one walk before, one during, and one after the photography activity) and during the group discussion. In addition, we made video recordings of the group activity and whole class activity. After the activity, we had stimulated recall interviews with these two students to obtain more information about their perception during the time they were wearing the glasses.

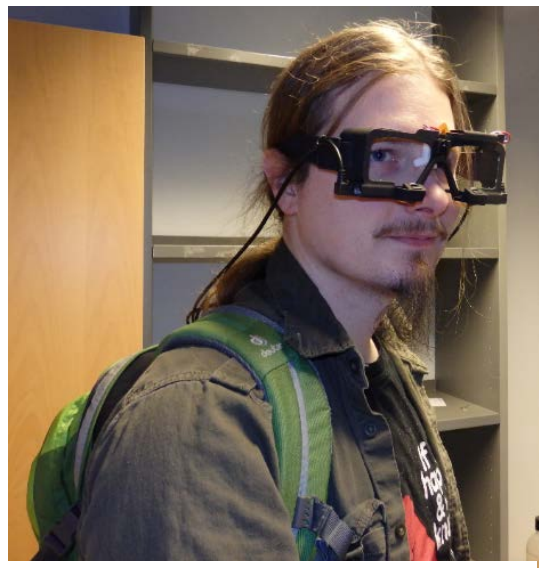

Figure 1. Gaze-tracking gear.

\subsection{Procedure}

The structure of our teaching activity is partly motivated by Pugh and Girod (2007) and is designed to let the students observe mathematics out-of-school-in a deep way with the goal of increased passion, interest, and understanding for their subject. We wished to give them the opportunity to make their own transformative, aesthetical experience.

We ran the same five-hour teaching activity in two different classrooms, with different teachers. The first author was teaching the elementary teacher group with the second author also present. Both groups answered the pre- and post-survey. The results from the first lesson of course design had indicated that the elementary teacher group had found the activity more inspiring. Therefore, we chose this group for deeper research.

After they finished the pre-survey, they were given the task to go out, "find mathematics" and take ten pictures with their mobile phone. To find objects of mathematical interest they had to observe in a deeper way than in everyday live (Barnbaum, 2010, Munakata, 2012).

After 15 minutes, when they were back, they were divided into randomly assigned groups of four. Firstly, they did some individual reflections on their 10 pictures, and chose one for further work. They were asked to write down the reason for taking this 
picture and to analyse the mathematics they connect to it. They continued with group discussions, where they shared their chosen picture, described it and reflected about the related mathematical ideas. They were also asked to discuss the possible use and value of this photography activity for mathematics education. Each group chose a picture to present to the whole class. In the group presentation the students were again asked to tell about the reason and the mathematics. After a short presentation, the whole class discussed and added further thoughts and ideas.

The post survey for the whole group had the same questions as the pre-survey and in addition some qualitative questions to extract deeper elaborations about the photography activity and work with the images.

\subsection{Research Design}

\subsubsection{Survey (quantitative and qualitative)}

Both groups did a quantitative survey before and after the activity. Moreover, the postsurvey included two open questions. With the survey, we wanted to examine participants' thoughts about mathematics teaching and mathematics as a subject, especially their thoughts about outdoor/ practical mathematics, creativity and the role of perception in mathematics teaching. The survey items were selected from View of Mathematics - questionnaire (Roesken, Hannula, \& Pehkonen, 2011) and some new items were designed to capture the specific features of the activity. The survey was designed with five Likert type items. It was anonymous, except for the two voluntary students who wore the gaze-tracking glasses.

\subsubsection{Gaze-tracking, audio, video and interview}

Gaze-tracking technology allows us to assess the visual attention of the participants. So far, the majority of gaze-tracking studies have been performed in laboratories. The MathTrack -project (Hannula, 2016, Hannula \&Williams, 2016) is one of the first full scale research projects to use several mobile gaze-trackers in a classrooms.

The mobile gaze-tracking glasses and algorithms used in this study were developed at the Finnish Institute of Occupational Health and released as open source (Toivanen, Lukander, \& Puolamäki, 2017). The device has been used in Hannula's studies, proving the promise of the technology in giving a deeper insight into students' visual attention as compared to the conventional video recordings (Hannula, 2016; Hannula \&Williams, 2016). 
The most typical eye movements are fixations and saccades (Land, 2011). We are interested in conscious and unconscious saccades. In a natural scene exploration, these can occur up to five times per second. When changing the attentional point, the eyes (and head) are moving towards it, not only in one but several saccades, many of them being unconscious.

Two voluntary students wore the gaze- tracking glasses (Figure 2), connected to a laptop carried in a backpack. The glasses contain three cameras; two pointing towards the eyes and the third one recording users scene. The software computes the gaze point (Figure 3) in the scene camera, using the eye camera data. In order to obtain good quality eye data, the students should have normal vision (no glasses/contact lenses or strabismus). Moreover, they could not use mascara.

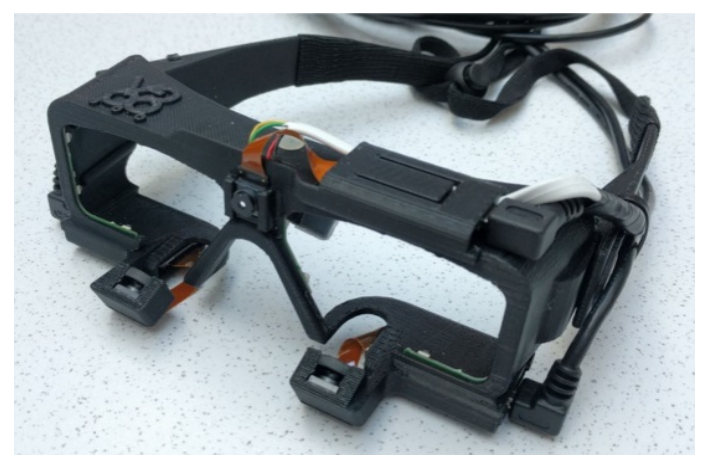

Figure 2. The gaze tracking glasses used in the study

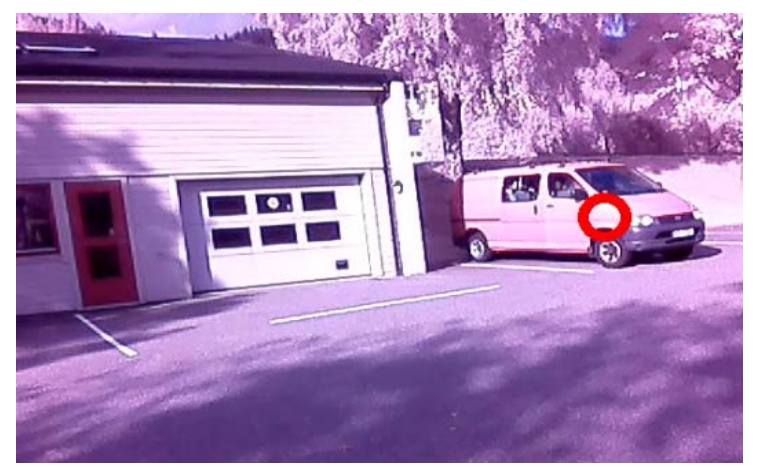

Figure 3. Estimated gaze point

Outdoor lighting conditions, especially direct sunlight, poses some challenges in the gaze tracking; pupil size decreases, extra reflections occur, the eye camera image may totally saturate, and the participants squint the eyes, all of which contribute to a deterioration the eye data. Hence, to avoid direct sunlight, we chose a shady path and the participants wore caps.

As the gaze-device does not record audio, the students wore microphones during the gaze tracking. On the walk during the photography activity the two students were instructed to go together and talk to each other. We wished to obtain some data of their communication.

We did video recordings of the group activity where the two voluntary students joined. The communication about their pictures could give interesting additional data. For the same reason we did a video recording of the whole class activity. There 
are many disturbing acoustical elements in a classroom during a group activity with several groups. Therefore, we decided to combine the video with audio recordings.

Pilot studies (Hannula, 2016) showed that an interview, together with the gaze tracking video as stimulus, is needed to do adequate analyses. After the third walk, we did a recall interview in two parts with each of the two students. In the first part, they did not see the gaze video. We wanted to know which kind of objects they remembered and whether they saw different objects after the photography activity and why they thought they saw something different. Secondly, we did a stimulated recall interview, showing the video from the gaze-tracking and asking the same questions. We did the interview in two parts to find out whether a visual stimulus will help them to remember what they saw. We took notes of the interview. After the analysis of the gaze-tracking videos, the teacher had follow-up interviews with the students.

\subsubsection{Notes and photographs from all students}

All students sent electronically the one photograph they had chosen for discussion to the teacher (the first author). They also wrote notes about the reason for taking their picture and the mathematics behind it. These responses varied in length from two sentences to half a page.

\subsection{Methods for data-analysis}

\subsubsection{Quantitative analyse of the survey with SPSS}

We formed theoretically based sum variables of survey items, but the reliability of the scales proved to be unsatisfactory, especially for the pre-survey. We assume that the low reliabilities for the pre-survey might be partly due to the students not perceiving the meaning of some of the items before the photography activity. After the activity, however, they seemed to have changed their perspective on teaching with photography. Because of the low reliabilities of the planned sum variables, we decided to analyse the data item by item.

We used reliability analysis to examine whether we can construct sum variables based on theoretical ideas regarding, for example, outdoor learning and aesthetics. When comparing the changes between pre- and post-survey, we used paired samples t-tests. 


\subsubsection{Qualitative analysis of the survey, together with notes and pictures}

The analysis of the open-ended questions in the survey started by making categories, related to our research focus: Outdoor/practical/everyday live, creative/ new ideas, visual attention, use of photography and mathematical concept, increased interest for mathematics. We then connected appropriate answers to every question of the quantitative analysis. To get more information about the possibilities for usage of this activity in mathematics classroom we also sorted the answers by items that appear in the Norwegian curriculum, for example algebra, geometry, statistics etc.

\subsubsection{Analysis of gaze-tracking video with the program ELAN}

Because of technical problems, we only had the video from Kari from the first and second walk and the video from Ola from the third walk. We looked through both videos several times and then decided to analyse Ola's video in detail. We named the objects and the duration of each gaze. In addition, we marked whether the objects were photographed by him or his partner, or discussed in the classroom work. We did not mark objects like the path he walked on. When he came to the stairs we could not be sure what kind of object it was for him. Asking him after the analysis, he said that the stairs he walked on were not an object of mathematical interest. We excluded the gazes on stairs for the time he was walking on them.

\subsubsection{Ethical reflections}

At the start of this project, we informed the students about the project and every student in the elementary teacher group signed an informed consent form for the use of data that might identify a person. Students had the option to change groups. Students who did not want to appear in a video were identified so that we could place them away from cameras and remove them in case they accidentally appear on video. The middle school teacher group was informed about the study, but no informed consent forms were used, as they only filled in the survey.

The first author was also a teacher. To avoid coercion the survey was returned anonymously. 


\section{$5 \quad$ Findings}

\subsection{Effects of the activity on student views}

A paired-samples t-test was conducted to compare items focusing specifically on outdoor learning (1), creativity (2), visual experiences (3), and photography (4 and 5) in the pre- and post-survey. In the scores for items on outdoor learning, creativity, or visual experiences, there was no significant difference. However, there was a significant difference in the scores for two items on photography indicating a more positive attitude towards using photography in mathematics teaching (Table 1).

Table 1. Paired-samples t-test.

\begin{tabular}{|c|c|c|c|c|c|c|c|c|}
\hline & & pre & & post & & Both & & \\
\hline Item & $N$ & Mean & SD & Mean & SD & $\begin{array}{l}\text { Pairwise } \\
\text { t-test }\end{array}$ & $d f$ & sig \\
\hline $\begin{array}{l}\text { 1. As often as possible, the teacher should } \\
\text { deal with tasks in which pupils make their } \\
\text { own practical experience outside the } \\
\text { classroom. }\end{array}$ & 47 & 3.96 & .75 & 4.09 & 0.88 & -1.182 & 46 & .243 \\
\hline $\begin{array}{l}\text { 2. In mathematics, one has to be creative to } \\
\text { come up with new ideas. }\end{array}$ & 47 & 3.81 & 0.92 & 4.04 & 0.88 & -1.756 & 46 & 0.086 \\
\hline $\begin{array}{l}\text { 3. Teachers should frequently use didactical } \\
\text { methods that include visual experiences. }\end{array}$ & 49 & 4.29 & 0.65 & 4.27 & 0.73 & 0.227 & 48 & 0.821 \\
\hline $\begin{array}{l}\text { 4. Students' perception of mathematics in } \\
\text { everyday contexts will increase through doing } \\
\text { photography. }\end{array}$ & 47 & 3.43 & 0.80 & 4.02 & 0.87 & -4.027 & 46 & 0.000 \\
\hline $\begin{array}{l}\text { 5. Students can learn mathematical concepts } \\
\text { by analysing pictures with mathematical } \\
\text { objects. }\end{array}$ & 49 & 3.82 & 0.73 & 4.45 & 0.71 & -5.310 & 48 & 0.000 \\
\hline
\end{tabular}

Based on Table 1 we will present the results of item 4 and 5 in detail. 


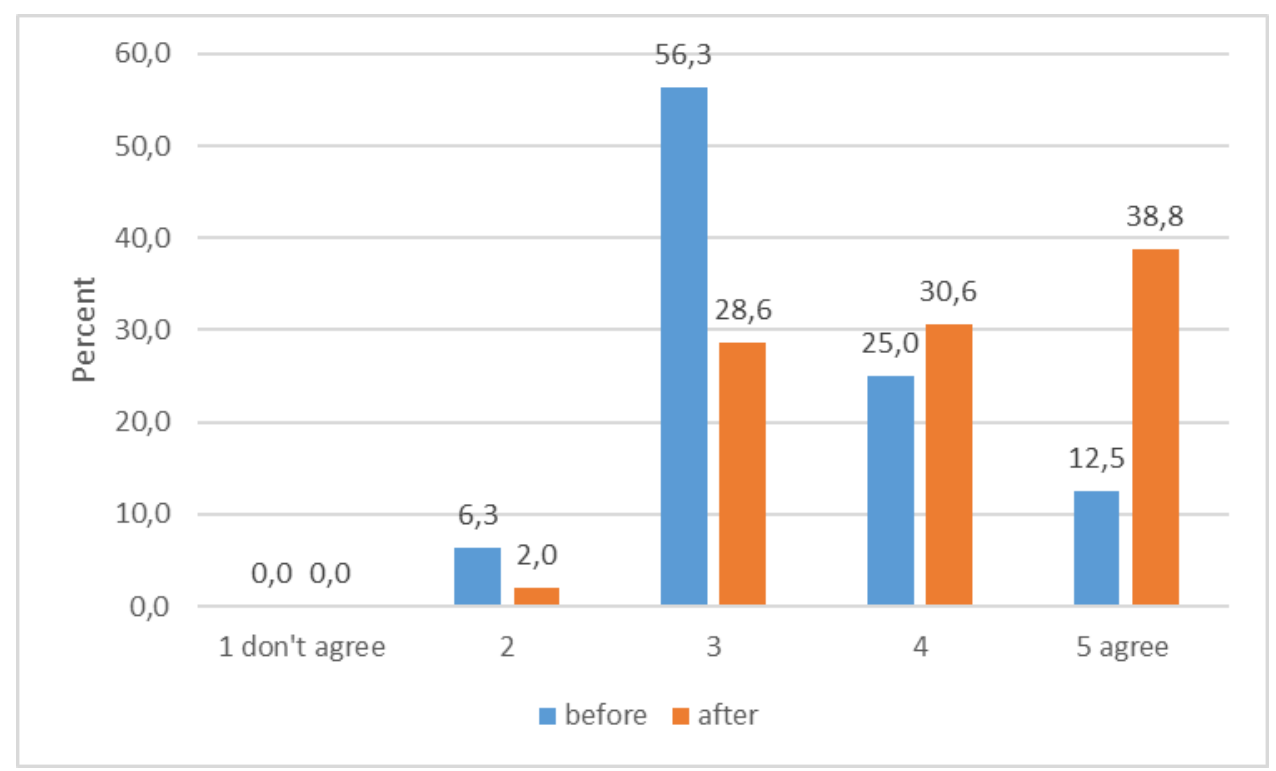

Figure 4. Responses to Item 4: Students' perception of mathematics in everyday contexts will increase through doing photography

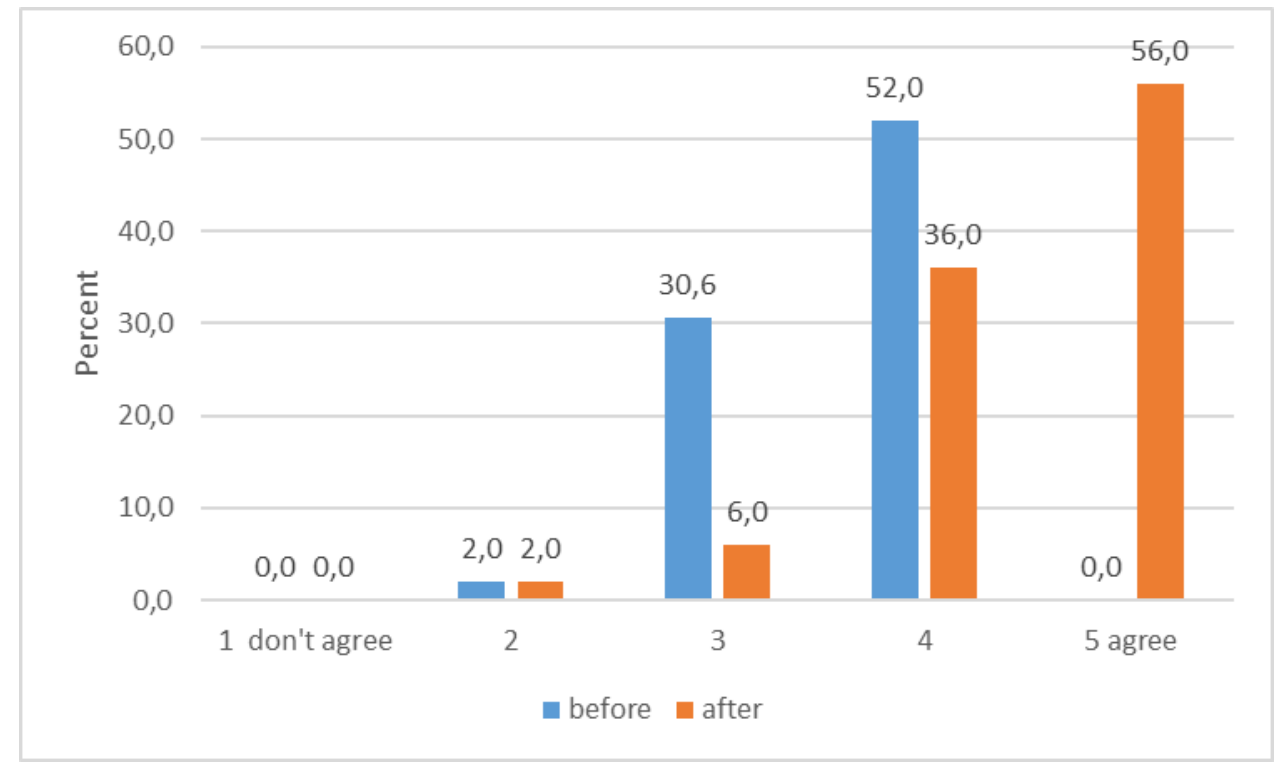

Figure 5. Responses to Item 5: Students can learn mathematical concepts by analysing pictures with mathematical objects.

The results of both specific photography questions (Figure 4 and 5) show an increase in positive answers after the activity. In Figure 4, they answered mostly in mid-scale before the activity. The reason can be that some students were not used to photographing and analysing pictures. They had no concrete idea before they had this experience. Afterwards, more students "fully agreed" that doing photography will increase students' perception of mathematics in everyday contexts, while even more 
students agreed that analysing pictures helps students to learn mathematical concepts.

The question is which mathematical concepts students can learn. Our participants gave possible applications to mathematics education (see the examples in Table 2) and emphasised that they could design tasks at all different levels.

Table 2. Examples - Photographs and mathematical concepts

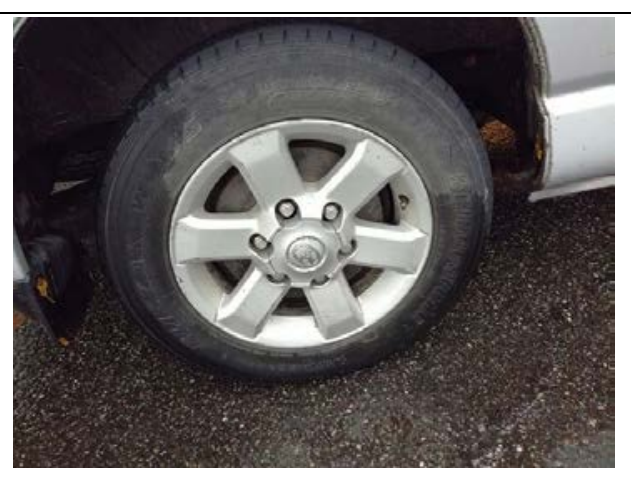

- Symmetry

- Geometry

- Perspective

- Arithmetic

- Interdisciplinary options with physics: Speed/ acceleration/ time

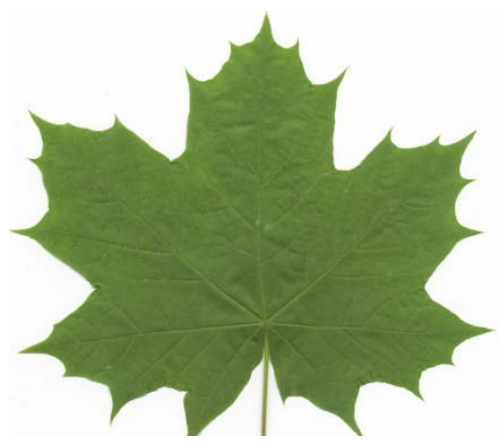

- Symmetry/ reflection

- Geometry: Perceiving the shape of the leaf, construction

- Number-theory

- Arithmetic - designing wordtasks

- Fibonacci number/golden ratio

- Interdisciplinary options with science/ art and craft.

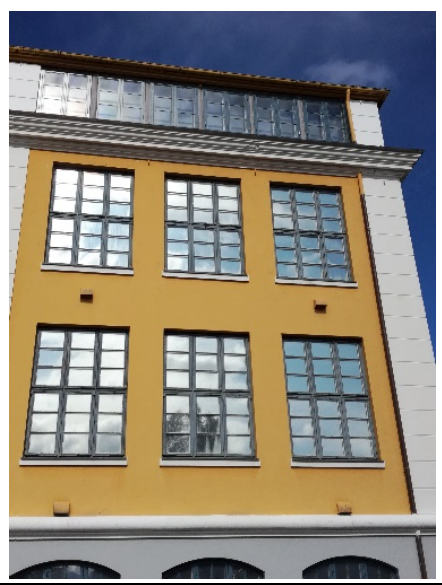

- Pattern

- Symmetry

- Counting and arithmetics

- Geometric shapes and calculation of areal and volume

- Measurement

- Economy

- Designing wordtasks 

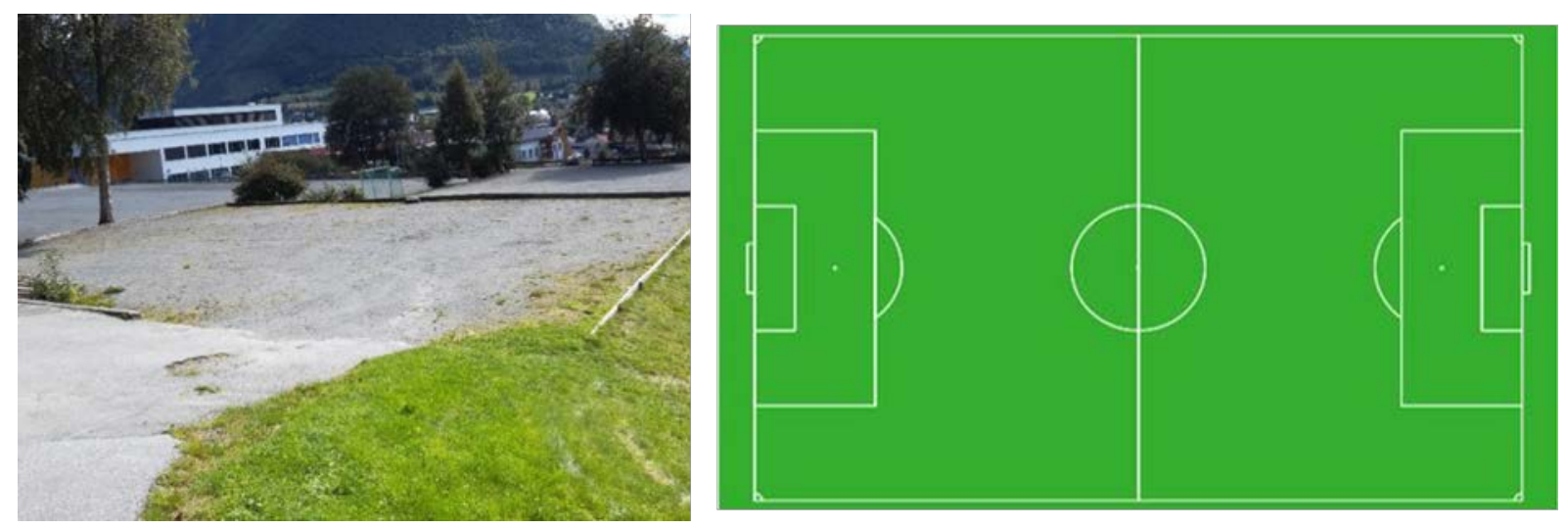

Figure 6. Ola presented his picture to the whole class and sketched the lines of a football pitch.

\begin{tabular}{lll}
\hline 1 & Ola & We chose my picture of a dirt pitch ... this could be a nice task, if one \\
2 & & could get a spraybox from the caretaker and paint the lines of the pitch. \\
3 & We had to paint a rectangle ... many terms ... and then you have to \\
4 & halve it [drawing], a new term. Then you have to make a circle \\
5 & [drawing] with a certain radius and diameter. You have to draw another \\
6 & rectangle [drawing on the left-hand side] and here too [drawing on the \\
7 & right-hand side]. We will measure that in metres, maybe in centimetres. \\
8 & And here are these half moons. This could be an extra challenge, \\
9 & however, I am not quite sure about how to do this. \\
10 & [pause: 5 seconds] \\
11 & And we have this one here, five metres ... [drawing two small rectangles \\
12 & in the goals]. And maybe these small penalty spots there, which are \\
13 & eleven metres from the goal. \\
14 & You can calculate the area, the circumference and teach about angles... \\
15 & & yes. ... these are some terms... \\
16 & Teacher & Yes, that is right. The image can be a starting-point to learn ... \\
17 & Ola & Yes, it is a very good practical task, I think, to involve the students in. \\
18 & Teacher & Because they are interested in football. \\
19 & Ola & Yes, absolutely. \\
20 & Teacher & Are there some more ideas from the group?
\end{tabular}

21 Birte ... volume ... how much gravel do we need ... just bought gravel that was expensive ... how much we have to buy. This could be suitable in the elementary school.

24 Helga Do you think of calculating the price?

25 Birte Yes

26 Teacher Is it possible to adjust it for a higher level?

Birte Yes, for the students who need an extra challenge.

Solveig Another task could be how many footballers are in a team. How many are they together at the field. 


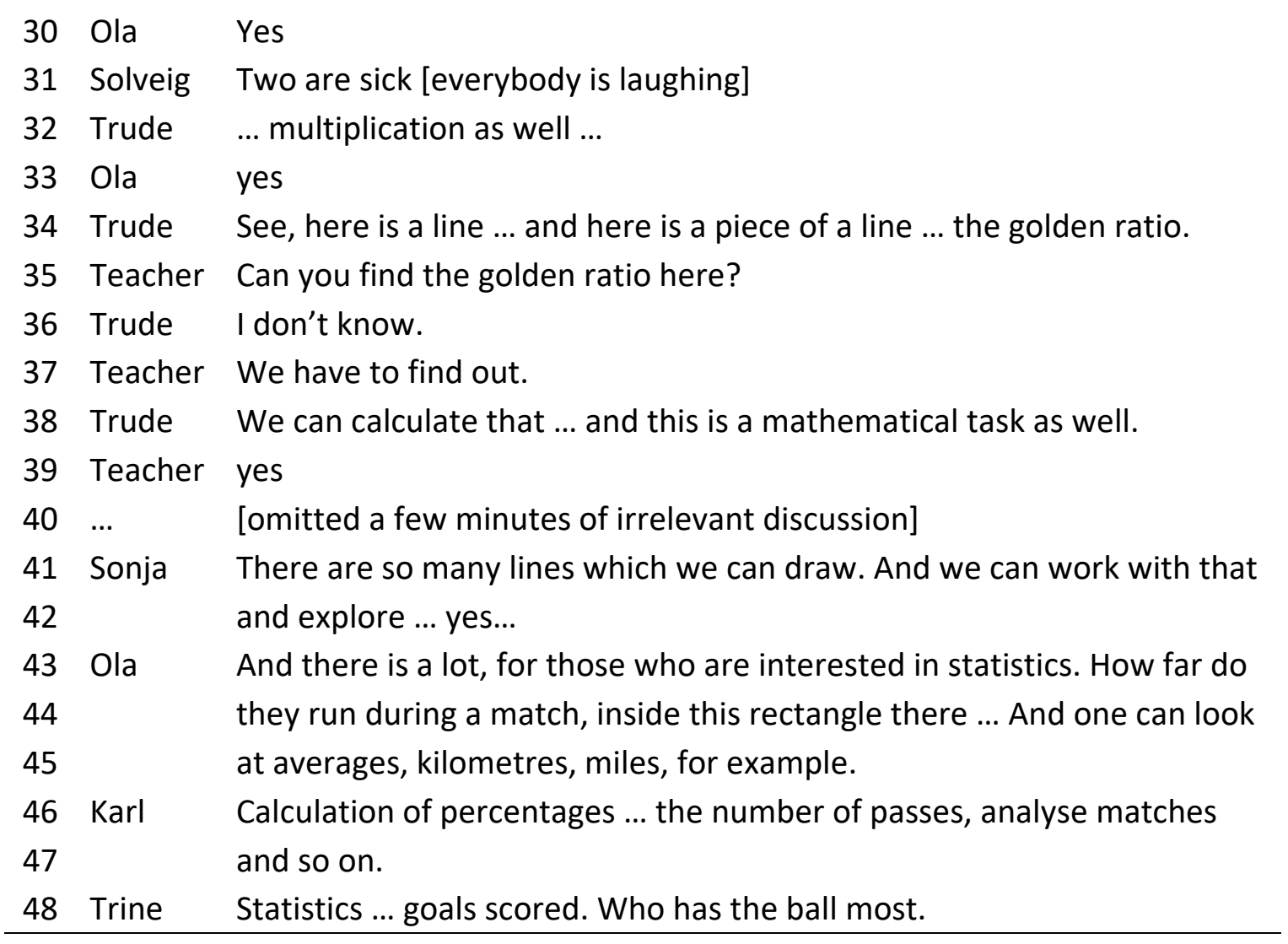

In the beginning Ola focuses mostly on geometry $(2-14)$ and measuring (7). Later other students had new ideas involving arithmetic (14, 28, 29, 31, 32), statistics (43 48), and economy (22-24). A picture from the outdoor world was the starting point for a rich discussion about applications in mathematical education.

In their written notes and during the presentations students mentioned several other topics that are important in the Norwegian mathematics curriculum, including algebra, probability, combinatorics, and functions.

\subsection{Results from the gaze-tracking videos, supplemented with the recall interview}

Because of the much stronger light in the outdoor conditions, the pupils of the students' eyes were small. The parametres had to be adjusted so that the eye pupils would be recognized.

In the video of Kari from the first walk, we observed that she mostly looked at the path and fixated on several objects, like houses, cars, people and so on, only for a very short time. In the recall interview, she said that she mostly paid attention to the path and the glasses, in addition to other people who could see her. She could not 
remember that she fixated on any special object. Nevertheless, we found that she had been looking at several objects that she photographed afterwards. It is interesting to notice that she did not remember these gazes in the interview.

We analysed Ola's video for the third walk (from exiting the building until reentering the building) in detail with ELAN and found some interesting results.

Table 3. Objects discussed/photographed or not

\begin{tabular}{lll}
\hline & Occurrences & average duration (s) \\
\hline Discussed/photographed & 197 & 0.63 \\
Not discusssed/not photographed & 33 & 0.41 \\
\hline
\end{tabular}

He focused more than five times as much on objects which were discussed or photographed.

Table 4. Occurrences and average duration of discussed/photographed objects

\begin{tabular}{llllll}
\hline Discussed/ taken picture of & \multicolumn{3}{l}{ Not discussed/ taken picture of } \\
\hline Object & Occurrences & $\begin{array}{l}\text { Average duration } \\
\text { (s) }\end{array}$ & Object & Occurrences & $\begin{array}{l}\text { Average duration } \\
\text { (s) }\end{array}$ \\
Car & 52 & 0.48 & Fence & 11 & 0.42 \\
House & 49 & 0.85 & Stairs & 3 & 0.63 \\
Lamppost/ & 24 & 0.29 & Motorcycle & 5 & 0.36 \\
flagpole & & & & & \\
Tree & 22 & 0.79 & Barrier & 3 & 0.47 \\
Window & 11 & 1.43 & Cycle rack & 3 & 0.30 \\
Dirt pitch & 10 & 0.51 & Machine & 2 & 0.98 \\
Sign & 10 & 0.35 & Leaf & 2 & 0.31 \\
Container & 7 & 0.32 & Log & 1 & 0.38 \\
Cycle & 5 & 0.73 & Tube & 1 & 0.37 \\
Playground & 4 & 0.60 & Student & 1 & 0.31 \\
Gully cover & 3 & 0.35 & Kajack & 1 & 0.23 \\
\hline Total & 197 & 0.63 & & 33 & 0.41 \\
\hline
\end{tabular}

The occurrence of cars and houses is highest (Table 4). In the discussion in the classroom, they had discussed images of car numbers, car rims, cars as objects for counting and sorting. In addition, houses were discussed in different ways. 
The rate for photographed or discussed objects was significantly higher than for the other objects (Table 3). However, there was one object, the fences, that attracted his attention quite often (Table 4). Asked about that, he said that he had not been aware of gazing at fences.

In the statistical analysis there was no significant difference in average gaze duration for the two groups of objects (Table 3). When we study details, he had longer attention on windows, a machine, houses and trees than for example on lampposts or flagstaff and cars (Table 4). He paid attention to cars and lampposts quite often, but not for a long time. The gaze on windows had a long average duration. He told us that they were quite interesting as mathematical objects.

This means that more often or longer visual fixation can be a sign of greater interest. However, the gaze-tracking video alone does not give explanations, so it was important to have the recall interview afterwards.

Additional observations: In the before-walk both did not notice much. Without seeing the gaze-video they could not remember a lot from the photography-walk. Seeing a stimulus video helped them to remember the objects that they had looked at and to explain their thoughts.

When they walked together, we expected them to talk about what they found and thought. Alas, they hardly ever did so. The two students worked in a quite different ways although both were very positive about the activity.

\section{Discussion}

The aim of our study was to explore the effect of photography-based teaching in outdoor conditions and our findings indicate that photography can be an appropriate tool in mathematics education. It seems that students' perception had shifted more towards mathematical objects after the intervention (Figure 4). Through their own experience they seem to have gained a renewed interest and excitement in mathematical concepts (Pugh and Girod, 2007). Everyday objects became mathematical objects through the experience of photography (Munakata and Vaidya, 2011). The students reflected upon the photographs and communicated new and creative teaching ideas. The results indicate that visualisation, or the art of re-seeing (Arcavi, 2003; Barnbaum, 2010; 2014), can be taught. Arcavi stated that visualisation could be a strong tool for learning mathematics. However, the mathematics content 
in our study was rather basic (Table 2). It seems that mathematizing was difficult for the students and they were not able to see more complex mathematics (e.g. fractals) in the surroundings. In a future study, we plan to have a warm-up activity for the students to attune them better for observing more advanced mathematics.

Barnbaum stated (2010, p. 58) that what we really see depends on our background. If we have more knowledge, training, and experience, we will see deeper. In our study, the students seemed to see and photograph objects which they were aware of from the beginning (for example cars and windows). On the other hand they photographed objects that they gazed at, but were not aware of (for example Kari saw houses and Ola fences). "Seeing without seeing" had an impact on their choices too. This finding might give an implication for education, both in general and mathematics: What children see and experience, also unconsciously (for example all kinds of media, toys, and environment), can become important for their future choices.

During the first walk with the gaze-tracking glasses, the students looked at objects only for a short time and in the later interview they did not remember what they had been looking at. The importance of visual information (video record) for the process of remembering was obvious. The data from the third walk, however, indicated a higher number of occurrences and longer gazes for objects previously photographed or discussed. To take pictures seemed to have an impact on the duration and occurrence of fixations of our gaze-tracking student. However, we do not know if he focused on mathematics, when he, for example, observed the cars 52 times.

In Barnbaums's terms, the progress might be seen as a move from "seeing without seeing" to "re-seeing". In Dewey's terms, we can understand it as the start to make an experience. To make the experience more complete and fulfilling a further study has to cover the whole process, from re-seeing to mathematizing.

The results from the survey show that most students made vital experiences in the sense of Dewey (Pugh and Girod, 2007, p. 16), from the process (to see and photograph) to the product (the images, analysis, and discussions). Boaler (2016, p. 3) claims that visual, open, and creative mathematical approaches can be appropriate to suit most students and at any level. Our findings show that they can be suitable for teacher education as well. We agree with Arcavi (2003, p. 215) that visualisation should play an important role in learning and doing mathematics. 


\subsection{Reflections on the gaze-tracking methodology}

In addition to evaluating the teaching unit, this study also explored the options and limitations of using mobile gaze-tracking in an outdoor-environment. Bright light and additional reflections were a potential problem. However, our data and analysis indicated that after adjusting computational parameters for smaller pupil size, gaze data in outdoor conditions is of good quality. We were unfortunate with technical problems unrelated to outdoor conditions and lost much of the data. In future studies it would be good to have more subjects to get data that are more complete. This will improve the options to compare the variations between the individuals in a controlled pre- and post-intervention comparison. However, the coding of the data is very time consuming and gives a limitation for the number of subjects. It will be important to find a more efficient and automatically coding system. That would help to analyse data from more individuals.

The gaze-tracking devices were influencing the student experience and behaviour to a minor extent. When outdoors, the students wearing the gaze trackers were aware of increased attention from other people. They also felt their visual field limited, for example when walking stairs. Taken together, it is seems plausible that wearing the gaze trackers influenced their visual attention to some extent. Moreover, as the teaching activity lasted for five hours, one student felt the goggles to be uncomfortable. Consequently, we allowed the students to take the device off after two hours and only wear it again for the third walk.

We are aware that gaze direction is not the same thing as target of attention. In addition to collecting gaze data, we asked the students to talk with each other (second walk), or to think aloud (third walk) when walking outdoors. Despite the instruction, they did not talk as much as we had expected. It is important in future studies to design better instructions for participants so that they would generate more verbal data. The interviews, both after the recording and after the analysis, were necessary to avoid wrong interpretation of the gaze data. For this reason, we were able to interpret, for example, the long fixation on the stairs as fixation on the path to walk on and not as an interesting mathematical object.

Despite the technical problems and methodological limitations described above, the gaze data provided us with a novel insight into students' visual attention in a natural outdoor setting. Firstly, we were able to get information about such attentional events that were either below the level of consciousness or forgotten 
immediately after the event. Kari fixated for example cars and the house, but could not remember this. Later she photographed these earlier seen objects. These events would not be accessible in a stimulated recall interview without gaze data. These findings about conscious and unconscious visual attention might be important for future educational research and development.

Moreover, even when students were aware of their gazing and recalled it afterwards, our quantitative data is more accurate.

We had gaze trackers for only two students and even their data were incomplete. We have no way to tell if these two case students were illustrative of other students' gazing behaviour. Hence, this study can be considered a methodological pilot, which was - despite technical problems - able to confirm the feasibility of mobile gaze tracking as a research methodology for outdoor mathematics.

\subsection{Developing the photography-based teaching activity and research further}

The activity was successful in helping the students re-see familiar objects (Barnbaum, 2010 , p. 58) with mathematical vision. The notes, answers from the survey and the video from the presentation show that there were many ideas for applications, both in different themes of mathematics education and in an interdisciplinary context. As the mathematical content was rather simple, the two different student groups should get different tasks in a future study. The 5-10 group needs the challenge for more advanced mathematics, as for example functions.

In table 4, we see the difference between fixations at discussed/not discussed or photographed objects. Further variations to study could be whether they or others photographed objects of visual interest.

Our results show that this activity seems to help students to see with "fresh eyes" (Wong, 2001, p. 329) and have a satisfactory learning experience in the Deweyan sense. To make the work even more complete and fulfilling, the process could be extended in a way, Munakata and Vaidya (2011) described. Their students designed a problem-solving task and the solution, based on a photograph, and presented their work in an exhibition. In a future project, students ought to go the whole way from the process to the product, from re-seeing, photographing, analysing, and reflecting about the photograph and mathematical content to designing a task and presenting their work. 


\title{
Acknowledgements
}

Arne Kåre Topphol (Volda University College) who helped with the SPSS work.

\author{
Jari Metsämuuronen (NLA University College Bergen) who double-checked the \\ reliability analyses.
}

\section{References}

Arcavi, A. (2003). The role of visual representations in the learning of mathematics. Educational Studies in Mathematics 52(3), 215- 241.

Barnbaum, B. (2010). The art of photography: An approach to personal expression. San Rafael, CA: Rockynook.

Barnbaum, B. (2014). The essence of photography: Seeing and creativity. San Rafael, CA: Rockynook.

Boaler, J ., Chen, L., Williams, C., \& Cordero, M. (2016). Seeing as understanding: The importance of visual mathematics for our brain and learning. J ournal of Applied \& Computational Mathematics 5(5). https:/ / doi.org/ 10.4172/2168-9679.1000325

Dewey, J . (1958). Art as experience. New York, NY: Perigee Books (original work published 1934).

Gravemeijer, K., Akker, J. Van Den, McKenny, S. \& Nieveen, N. (2006). Educational design research. NewYork, NY: Routledge.

Hannula, M. S. (2016). The Eye on the Mathematics: Findings from a Pilot Study Using Mobile Gaze Tracking. In M. Lepik (Ed.), Teaching Mathematics: Retrospective and Perspectives, Proceedings of the 17th International Conference, Tallinn University, May 6- 7, 2016. (pp. 43- 57). Tallin, Estonia: Institute of Digital Technologies, Tallinn University.

Hannula, M. S., \& Williams, G. (2016). Silent gazing during geometry problem solving, insights from eye tracking. In C. Csíkos, A. Rausch, \&J . Szitányi (Eds.) Proceedings of the 40th Conference of the International Group for the Psychology of Mathematcics Education Volume 2 (pp. 353-360). Szeged, Hungary: PME.

J ackson, P. W. (1998). J ohn Dewey and the lessons of art. New Haven, CT: Yale University Press.

Kramer, M. (2013). Mathematik als Abenteuer [Mathematics as adventure]. Hallbergmoos, Germany: Aulis Verlag.

Land, M. F. (2011). Oculomotor behaviour in vertebrates and invertebrates. In S. P. Liversedge, I. Gilchrist, \& S. Everling (Eds.), The Oxford handbook of eye movements (pp. 121-132). Oxford, UK: Oxford University Press.

Munakata, M., \&Vaidya, A. (2012). Encouraging creativity in mathematics and science through photography. Teaching Mathematics and its Applications: An International J ournal of the IMA, 31(3), 121- 132.

Pallant, J . (2013). SPSS Survival Manual. Berkshire, UK: Open University Press.

Pugh, K. J., \& Girod, M. (2007). Science, art, and experience: constructing a science pedagogy from Dewey's aesthetics. J ournal of Science Teacher Education 18(1), 9- 27. https:/ / doi.org/ 10.1007/ s10972-006-9029-0

Regjering. (2017, September 1). Overordnet del: Verdier og prinsipper for grunnopplæringen [General part: Values and principles for basic education]. Retrieved from 
https:/ / www.regjeringen.no/ contentassets/ 37f2f7e1850046a0a3f676fd45851384/ overordn et-del---verdier-og-prinsipper-for-grunnopplaringen.pdf

Roesken, B., Hannula, M. S., \& Pehkonen, E. (2011). Dimensions of students' views of themselves as learners of mathematics. ZDM, 43(4), 497- 506. https:/ / doi.org/ 10.1007/ s11858-0110315-8

Toivanen, M., Lukander, K., \& Puolamäki, K. (2017). Probabilistic Approach to Robust Wearable Gaye Tracking. J ournal of Eye Movements research 10(4), 2.

Wong, D., Pugh, K., \& Group, T. D. (2001). Learning science: A Deweyan perspective. J ournal of Research in Science Teaching, 38(3), 317- 336. 